\title{
Ectopic expression of the phosphomimic mutant version of Arabidopsis response regulator 1 promotes a constitutive cytokinin response phenotype
}

Jasmina Kurepa ${ }^{2}$, Yan $\mathrm{Li}^{1,2}$, Sharyn E Perry ${ }^{2}$ and Jan A Smalle ${ }^{2^{*}}$

\begin{abstract}
Background: Cytokinins control numerous plant developmental processes, including meristem formation and activity, nutrient distribution, senescence timing and responses to both the abiotic and biotic environments. Cytokinin signaling leads to the activation of type-B response regulators (RRBs), Myb-like transcription factors that are activated by the phosphorylation of a conserved aspartate residue in their response receiver domain. Consistent with this, overexpression of RRBs does not substantially alter plant development, but instead leads to cytokinin hypersensitivity.

Results: Here we present comparative analysis of plants overexpressing Arabidopsis RRB 1 (ARR1) or a phosphomimic ARR1 ${ }^{\text {D94E }}$ mutant in which the conserved aspartate-94 (D94) is replaced by the phosphomimic residue glutamate (E). The D94E substitution causes a 100-fold increase in response activation and instigates developmental and physiological changes that characterize wild-type plants treated with cytokinins or transgenic plants with increased cytokinin content.

Conclusion: The current model of cytokinin signaling emphasizes the essential role of conserved aspartate residue phosphorylation of RRBs in promoting cytokinin responses. Our comparative analyses of developmental and physiological traits of ARR1 and ARR1 ${ }^{\text {D94E }}$ overexpressing plants revealed that the ARR1 ${ }^{\mathrm{D} 94 \mathrm{E}}$ protein is indeed a constitutive and wide-spectrum cytokinin response activator.
\end{abstract}

Keywords: Arabidopsis, Cytokinin signaling, Type-B response regulator, Phosphomimic mutation, Constitutive hormone response

\section{Background}

Cytokinins are a class of hormones that play essential roles in plant development and plant responses to the environment [1-5]. The cytokinin response pathway resembles two-component signaling mechanisms from yeast and bacteria [6]. The core cytokinin signaling pathway in Arabidopsis involves the actions of four components: the histidine kinases (CHKs), histidine phosphotransfer proteins (HPTs), and two antagonistically acting classes of response regulators (RRs) that control the gene expression

\footnotetext{
*Correspondence: jsmalle@uky.edu

2Plant Physiology, Biochemistry, Molecular Biology Program, Department of Plant and Soil Sciences, University of Kentucky, 1401 University Drive, Lexington, KY 40546, USA

Full list of author information is available at the end of the article
}

outputs of the pathway [6-10]. The signaling cascade starts with cytokinin binding to a $\mathrm{CHK}$ receptor, resulting in its autophosphorylation at a conserved histidine [6,11-14]. The phosphate group is then transferred to a conserved aspartate residue of the receptor's receiver domain, and then from the receiver domain to a histidine residue in a HPT [6,15-17]. The phosphorylated HPT relays the phosphate to an aspartate residue in the receiver domain of type-B RR (RRB). Phosphorylation of RRBs is thought to activate them and promote cytokinin action by up-regulating the expression of cytokinin response genes $[6,18,19]$. One class of transcriptional targets of activated RRBs are type-A $R R(R R A)$ genes [20-23]. RRAs are also phosphorylated by HPTs, which increases their
C Biomed Central

(c) 2014 Kurepa et al.; licensee BioMed Central Ltd. This is an open access article distributed under the terms of the Creative Commons Attribution License (http://creativecommons.org/licenses/by/2.0), which permits unrestricted use, distribution, and reproduction in any medium, provided the original work is properly cited. 
activity and, at least for some members, decreases their degradation rate [24]. Since RRAs act as cytokinin response inhibitors, their cytokinin-induced transcription combined with their cytokinin-dependent activation and stabilization leads to suppression of cytokinin action, thus limiting the strength and the duration of the cytokinin response [20,25,26].

In addition to the core signaling components, the cytokinin response pathway in Arabidopsis involves other positive and negative regulators. For example, Arabidopsis HPT6 (AHP6) is similar in sequence to other HPTs, but lacks the conserved histidine needed for the phosphorelay. As a result, AHP6 acts as an inhibitor of cytokinin responses probably by causing competitive inhibition through its binding with the CHKs, RRBs or both [27]. Another example is AXR1 (auxin resistant 1), a key enzyme in the related to ubiquitin (RUB) pathway of protein modification, which promotes the cytokinin response by suppressing the accumulation of the RRA member ARR5 [28]. The GeBP (GL1 enhancer binding protein) and GeBP-like proteins are leucine-zipper transcription factors that promote the cytokinin response by limiting the induction of RRA genes [29]. The cytokinin response factors (CRFs) belong to the APETALA2/ethylene responsive factor class of transcription factors and act in parallel to the RRBs in controlling cytokinin response genes [30].

The complexity of the cytokinin signaling pathway is further increased by the existence of multigene families encoding all four core signaling components [15,21,31-34]. Although the current data show that the functional redundancy within these gene families is quite extensive, there is also compelling evidence to suggest some degree of functional diversification $[18,19,23,35,36]$. To date, two types of functional diversification have been described. First, within all four gene families, members are differentially transcribed both in a tissue- and signal-specific manner, and in terms of relative abundance [37-40]. Second, although proteins within each family share a high degree of identity, their diverged regions are variable enough to offer specific ligand binding affinities or participation in different cellular responses [40-43].

The Arabidopsis RRB family contains 11 members that belong to three phylogenetic groups [19]. All RRBs have a $\mathrm{N}$-terminal receiver domain that includes a conserved aspartate needed for the phosphorelay, a centrally positioned Myb-like DNA binding domain, and a variable domain at the C-terminus which is thought to be responsible for the functional specialization within this family $[33,41,43]$. Loss-of-function studies with single, double and higher-order mutants have revealed not only a high level of functional redundancy, but also that $A R R 1$, ARR10, ARR11 and ARR12 control most of the cytokinin response $[23,35,44,45]$. Other RRBs are believed to control cytokinin responses in specific tissues or at particular developmental stages. For example, $A R R 2$ is predominantly expressed in pollen [46].

Over expression of RRBs leads to cytokinin hypersensitivity, but causes minor changes in plant development $[6,18,47]$. Based on the analogy with bacterial twocomponent systems, these observations led to the hypothesis that RRBs are expressed in their inactive forms and that cytokinin promotes the RRBs activation by phosphorylation of a conserved aspartate residue. Indeed, comparative analyses of protoplast expressing wild-type ARR2 and the ARR2 $2^{\text {D80N }}$ loss-of-phosphorylation mutant showed that the cytokinin-dependent induction of the $R R A$ gene $A R R 6$ is reduced in protoplast expressing the ARR2 ${ }^{\mathrm{D} 80 \mathrm{~N}}$ form and that a gel-mobility shift of the ARR2 protein consistent with its phosphorylation is not detectable in the ARR2 ${ }^{\text {D80N }}$ expressing protoplasts [42]. Studies of twocomponent signaling systems in bacteria, yeast and plants have shown that a response regulator can be rendered constitutively active if the conserved aspartate is mutated into the phosphomimic residue glutamate [42,48-51]. Indeed, when a $35 S: A R R 2^{D 80 E}$ transgene was expressed in Arabidopsis, plants were dwarfed and their $R R A$ genes were constitutively up-regulated [51]. The crucial role of the conserved aspartate for the activation of RRBs was also described in a study of the ARR18 family member [52]. A phosphomimic substitution ARR $18^{\mathrm{D} 70 \mathrm{E}}$ also caused a constitutive cytokinin response with respect to the transcriptional induction of primary cytokinin response genes. The effects of phosphomimic ARR18 or ARR2 mutations on cytokinin-regulated developmental and physiological processes were not analyzed $[51,52]$.

Thus, the current data offer little information regarding the effects of overexpressing active, phosphorylated RRBs on intact plants and we still lack final proof that phosphorylation of RRBs is sufficient to promote all the developmental and physiological processes that characterize cytokinin response. To address this issue, we introduced the phosphomimic amino acid substitution D94E in ARR1, one of the major Arabidopsis RRBs, and ectopically expressed the mutant protein in arr1-1 mutant plants. We show that Arabidopsis seedlings expressing ARR $1^{\text {D94E }}$, but not the unmodified ARR1, resemble cytokinin-treated wild-type plants in a transgene dose-dependent manner. Furthermore, our analyses reveal that all of the tested cytokinin responses were constitutively up-regulated in 35S:ARR $1^{D 94 E}$ plants. Together, our results show that the $A R R 1^{D 94 E}$ protein is a wide-spectrum cytokinin response activator.

\section{Results and discussion}

\section{The phosphomimic D94E substitution promotes a} 100-fold increase in ARR1 activity

To compare the capacity of different ARR1 versions to promote cytokinin responses in the absence of cytokinin 
treatments, we generated plants expressing wild-type ARR1 and the phosphomimic ARR1 ${ }^{\text {D94E }}$ in the arr1-1 background (Figure 1). Based on the results of immunoblotting screens of transgenic lines, we selected two $35 \mathrm{~S}$ : $A R R 1^{D 94 E}$ and three 35S:ARR1 lines for further analyses. The two phosphomimic lines contained $\sim 5 \pm 1$ and $\sim 14 \pm$ 2 more ARR1 compared to Col- 0 plants of the same age, and are here referred to as low $(\mathrm{L})$ and high $(\mathrm{H})$ expressors (Figure 1A, B). The three lines expressing wild-type ARR1

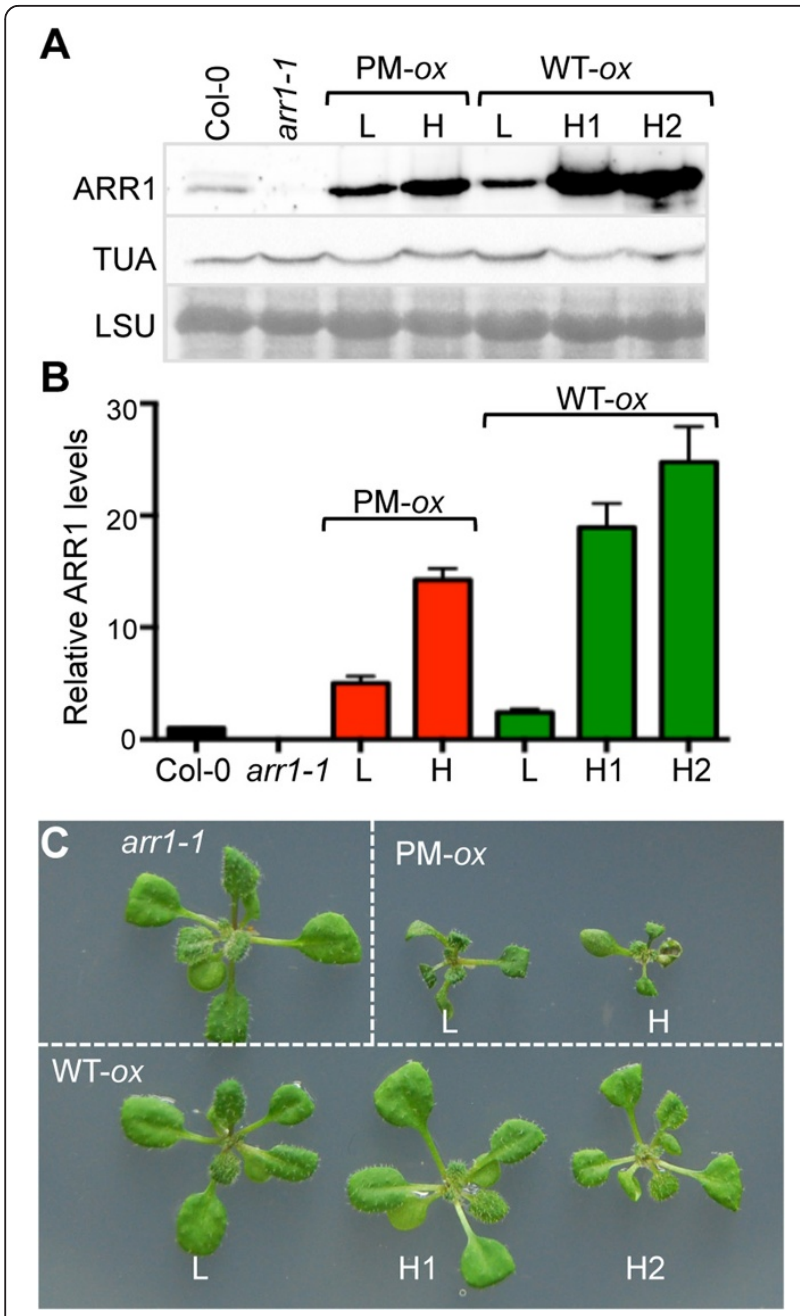

Figure 1 Analyses of ARR1 expression levels in phosphomimic 35S:ARR1 ${ }^{\text {D94E }}$ (PM-ox) and 35S:ARR1 (WT-ox) lines and the characteristic dwarf phenotype of $35 S: A R R 1^{D 94 E}$ plants. (A) The ARR1 levels in the Col-0 wild type, the arr1-1 mutant and the overexpression lines generated in the arr $1-1$ background were determined using anti-ARR1 antibody. Immunoblotting analysis with the anti-a-tubulin (TUA) antibodies and the image of the region of the Ponceau S-stained membrane surrounding the large RuBisCO subunit (LSU) are shown as controls. L, low and H, high expression levels. (B) Quantification of ARR1 expression levels. Chemiluminescent ARR1 signals were normalized to TUA and results are expressed as fold increase compared to Col-0, which was assigned a value of 1. Data are presented as mean \pm SEM of two independent experiments. (C) Rosettes of representative two-week-old plants grown on MS/2 media. contained $\sim 2.5 \pm 0.5,18 \pm 4$ and $24 \pm 4$ more ARR1 compared to Col-0, and are referred to as low (L) and high (H1 and H2) expressing lines, respectively (Figure 1A, B). Despite similar expression levels of phosphomimic and wild-type ARR1 in the $\mathrm{H}$ lines, only transgenic plants expressing phosphomimic ARR1 had rosettes smaller than Col-0 and arr1-1 (Figure 1C). Reduced rosette size is one of the characteristic developmental phenotypes associated with exogenous cytokinin treatments and cytokinin overproduction $[18,53]$.

Inhibition of root growth is one of the most sensitive organismal responses to cytokinin [4,54]. Consistent with the effect of the transgene on rosette size, roots of plants expressing phosphomimic ARR1 were shorter than roots of arr1-1 plants (Figure 2A). We also observed a dose-dependent effect of the phosphomimic ARR1 transgene: roots of the $L$ line were $\sim 2$-fold longer than roots of the $\mathrm{H}$ seedlings. The root length of plants expressing the wild-type ARR1 was affected only in the strongest expressor line (i.e., H2), and to a lesser extent compared to the phosphomimic ARR1-expressing lines (Figure 2A).

We next estimated the strength of the cytokinin effect caused by the ectopic expression of wild-type and phosphomimic ARR1 versions by comparing the transgenic root lengths with those of the wild-type and arr1-1 plants grown on MS/2 media supplemented with a range of benzyladenine (BA) doses (Figure 2B). The 35S:ARR1 $1^{D 94 E}$ lines showed a constitutive cytokinin response phenotype, with the $\mathrm{L}$ and $\mathrm{H}$ lines resembling wild-type seedlings treated with $20 \mathrm{nM}$ BA and $0.5-2 \mu \mathrm{M}$ BA, respectively (Figure 2B). In agreement with the observed decrease in cytokinin sensitivity of the arr1-1 mutant [18], the BA concentration that promoted a similar root growth inhibition was higher (100 nM vs. $20 \mathrm{nM}$ for arr1-1 and Col-0 respectively; Figure 2B). Analyses of the lines expressing wild-type ARR1 showed that only the highest expressor $\mathrm{H} 2$ had a weak constitutive cytokinin response phenotype which resembled wild-type plants grown on $5 \mathrm{nM}$ and arr1-1 plants grown on $20 \mathrm{nM}$ BA (Figure 1B). To obtain an estimate of the difference in response activation between ARR1 and ARR1 ${ }^{\mathrm{D} 94 \mathrm{E}}$, we compared the BA doses that phenocopied the root length of the $\mathrm{H}$ phosphomimic and the $\mathrm{H} 2$ wild-type ARR1 lines. Because the ARR1 level in the wild-type expressor line $\mathrm{H} 2$ is higher than in the phosphomimic $\mathrm{H}$ line (Figure 1A, B), this comparison represents an estimate of the minimal relative response activation strength of the phosphomimic ARR1 ${ }^{\mathrm{D} 94 \mathrm{E}}$. Since phosphomimic ARR1 $\mathrm{H}$ seedlings resembled the wild type grown on $0.5 \mu \mathrm{M}$ BA and wild-type ARR1 H2 seedlings resembled the wild type on $5 \mathrm{nM} \mathrm{BA}$, we concluded that the ARR1 ${ }^{\mathrm{D} 94 \mathrm{E}}$ protein is at least 100 -fold more potent in promoting this cytokinin response. 


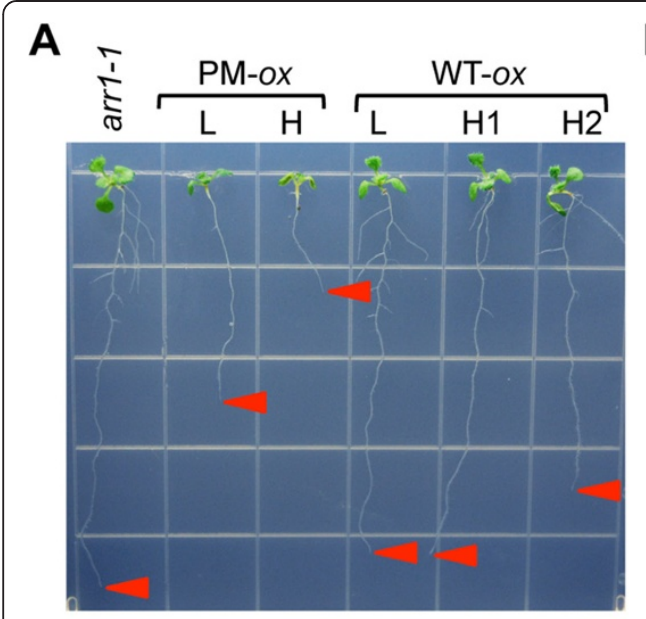

B

Figure 2 Quantification of cytokinin response strength in ARR1 overexpressing lines. (A) Representative ten-day-old arr1-1, 35S:ARR1 (WT-Ox) and 35S:ARR1 D94E (PM-OX) seedlings grown on MS/2 medium. The arrows point at the root tips. (B) Quantification of root elongation growth. Three-day-old transgenic seedlings grown on MS/2 plates were transferred to fresh MS/2 plates. In parallel, three-day-old Col-0 and arr 1-1 seedlings were transferred MS/2 plates containing the indicated concentrations of BA. The root length of each seedling was marked at the moment of transfer (initial length) and after 7 days of growth on test media (final length). Root elongation (difference between final and initial root length) of 30 seedlings per line is presented as a dose-response curve for Col-0 and arr 1-1 and as bars (mean \pm SD) for the transgenic lines. The results were analyzed using one-way analysis of variance (ANOVA) followed by Tukey's multiple comparisons test. The Col-0 and arr 1-1 root lengths that did not significantly (ns) differ from the root length of the transgenic line are encircled.

\section{Ectopic expression of ARR ${ }^{\text {D94E }}$ promotes a wide spectrum of constitutive cytokinin responses}

To document the extent of the constitutive response in the phosphomimic lines, we next analyzed other cytokininregulated traits in wild-type ARR1 and phosphomimic ARR1 expressing lines. First, we determined the steadystate mRNA levels of two cytokinin-inducible genes. The $R R A$ gene $A R R 5$ is a primary cytokinin response gene and encodes an inhibitor of the cytokinin response [20,25,26]. The cytokinin-inducible EXP1 gene is thought to act further downstream in the cytokinin response pathway, and it encodes a cell-wall loosening protein expansin 1 [55]. Consistent with the constitutive cytokinin response phenotype, the steady-state levels of both ARR5 and EXP1 were up-regulated by the phosphomimic $A R R 1$ transgene (Figure 3). We observed a significant increase in ARR5 abundance in the phosphomimic ARR1 $\mathrm{H}$ line, while the EXP1 transcript level was higher in both phosphomimic ARR1 lines. In comparison, the expression of both cytokinininducible genes was not increased in the wild-type ARR1 expressing lines (Figure 3).

Second, we tested the root hair elongation response which is known to be promoted by exogenous cytokinin [54] and increased in the cytokinin overproducer line ipt-161 [28]. Both phosphomimic ARR1 lines had a constitutive root hair elongation response which was transgene dose-dependent (Figure 4). In contrast, no increased root hair elongation was observed in the ARR1 expressing lines. In agreement with the observed decrease in cytokinin sensitivity of the arr1-1 mutant [18], the root hair length in the arr1-1 mutant was reduced compared to the wild type (Figure 4).

Next we tested the cytokinin responses of transgenic lines grown in darkness. Previous studies have identified two types of cytokinin growth responses in etiolated seedlings [56]. At an early stage of etiolated growth (3 to 5 days of dark incubation), cytokinin-treated seedlings have a shorter hypocotyl and an increased apical hook curvature, whereas at later stages (e.g., after 4 weeks), cytokinin-treated seedlings have swollen upper hypocotyls regions, expanded cotyledons and have developed true leaves [56,57]. The untreated wild type and arr1-1 seedlings did not differ from each other and displayed the expected etiolated development that is characterized by an elongated hypocotyl and small yellow unopened cotyledons (Figure 5A). In contrast, the 35S:ARR1 $1^{D 94 E}$ plants again exhibited a constitutive cytokinin-response phenotype when grown in darkness (Figure 5). After 4 days of growth in the dark, both 35S:ARR1 $1^{D 94 E}$ lines had shorter hypocotyls and an exaggerated apical hook curvature, and resembled the cytokinin-treated wild-type and ipt-161 seedlings (Figure 5A, B). After 4 weeks of growth in the dark, both the 35S:ARR1 $1^{D 94 E}$ and ipt-161 seedlings had expanded cotyledons, swollen upper hypocotyls regions and had formed true leaves, again resembling the cytokinin-treated wild type (Figure 5C, D). Contrary to the effect of exogenous cytokinin on the wild type, we did not observe a reduction in root elongation in any of the etiolated seedlings, including the cytokinin overproducer ipt-161 (Figure 5A). The lines expressing the wild-type 


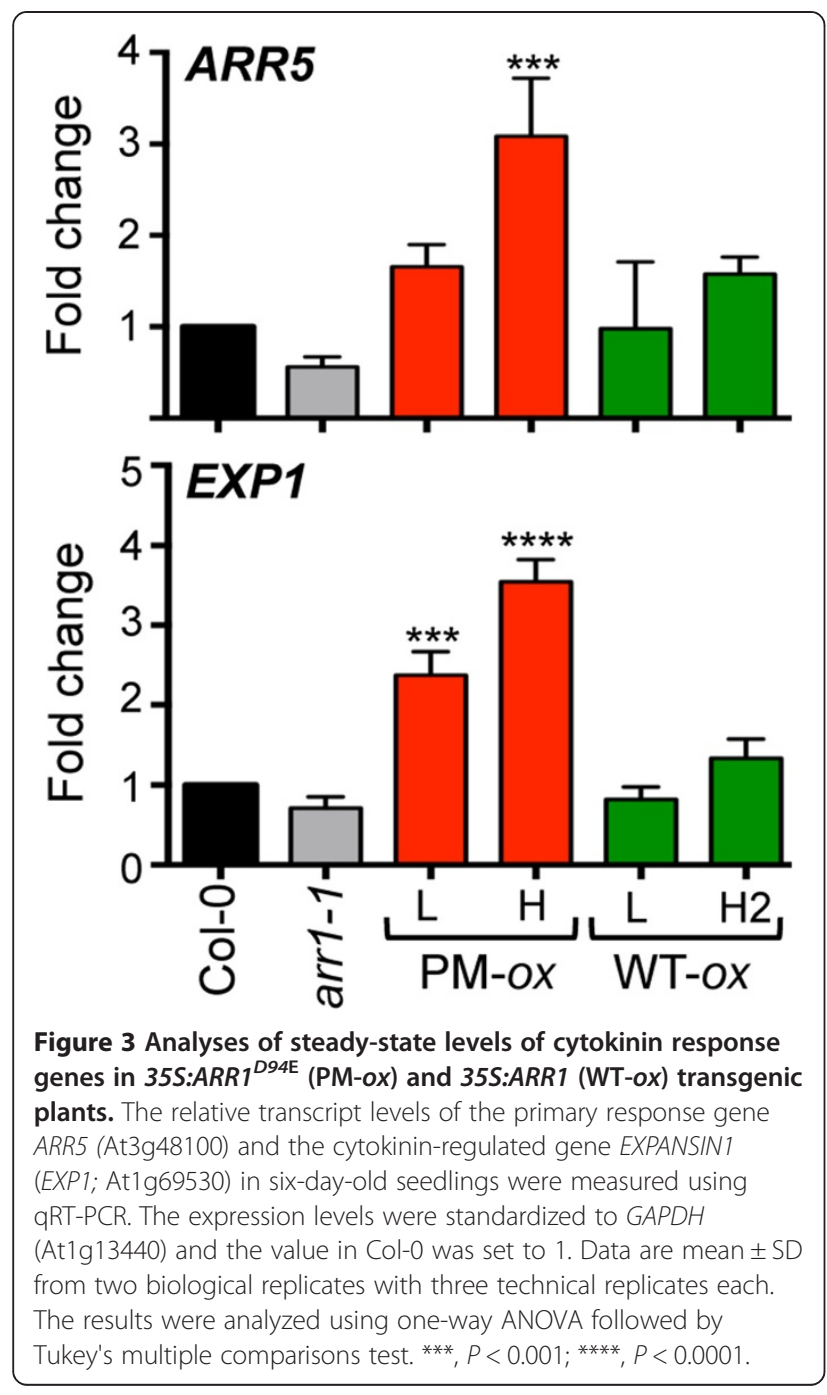

ARR1 did not display any constitutive response phenotype either at the early or late etiolated development stages (Figure 5).

The fourth test we conducted is the analyses of hypocotyl and root explants responses to auxin (Figure 6). Incubation of explants on media supplemented with particular concentration ratios of auxin and cytokinin are known to promote callus or shoot formation [58]. Typically, a high cytokinin-to-auxin ratio will promote the formation of green calli and the occasional shoot development. In contrast, a lower cytokinin-to-auxin ratio will promote the growth of only white calli or if the ratio drops below a critical threshold, no cell proliferation at all. In theory, a constitutive cytokinin response mutant or a cytokinin overproducer would not require cytokinin in the media for callus or shoot formation. Indeed, after 28 days of incubation on media containing only $0.1 \mu \mathrm{M}$ NAA, hypocotyls excised from 35S:ARR1 $1^{D 4 E}(\mathrm{H})$ and ipt-161 seedlings developed green calli (Figure 6). Higher concentration of NAA $(0.5 \mu \mathrm{M})$ promoted green callus

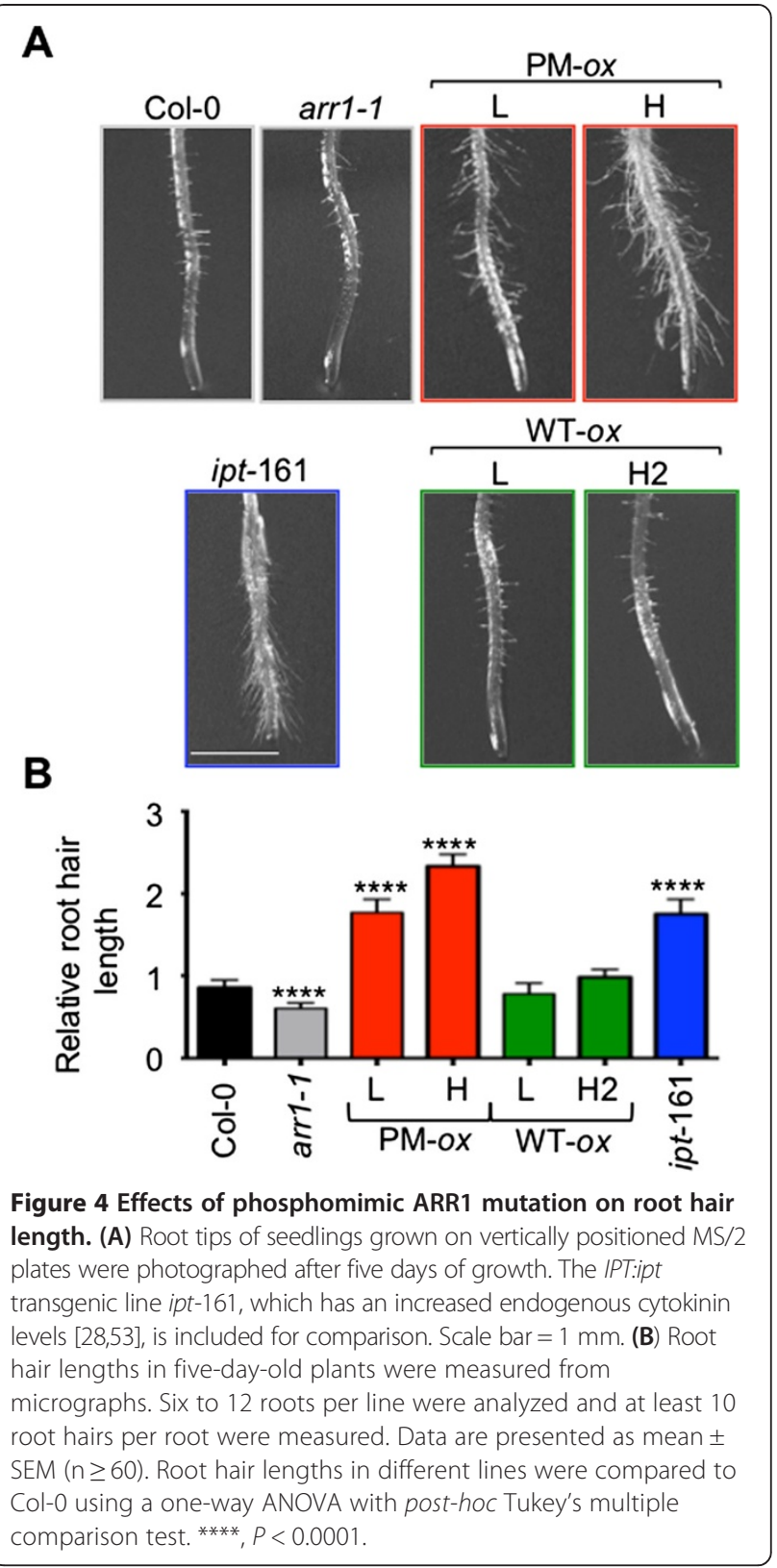

and shoot formation in both phosphomimic lines and in ipt-161 (Figure 6). As expected, no cell proliferation was observed in wild-type and arr1-1 hypocotyls on any of the auxin concentrations tested. We also did not observe any callus or shoot induction responses in the wild-type ARR1 overexpressing lines confirming that these lines do not have a constitutive cytokinin response (Figure 6). Therefore, the cell proliferation response to auxin required either an increase in endogenous cytokinin or a constitutive up-regulation of ARR1 action. Because the cell proliferation and differentiation was more pronounced in the strong 35S:ARR1 ${ }^{D 94 E}$ compared to the weak 35S:ARR1 $1^{D 94 E}$ line, we concluded that the relative response strengths were a reflection of the difference in ARR $1^{\mathrm{D} 94 \mathrm{E}}$ expression 

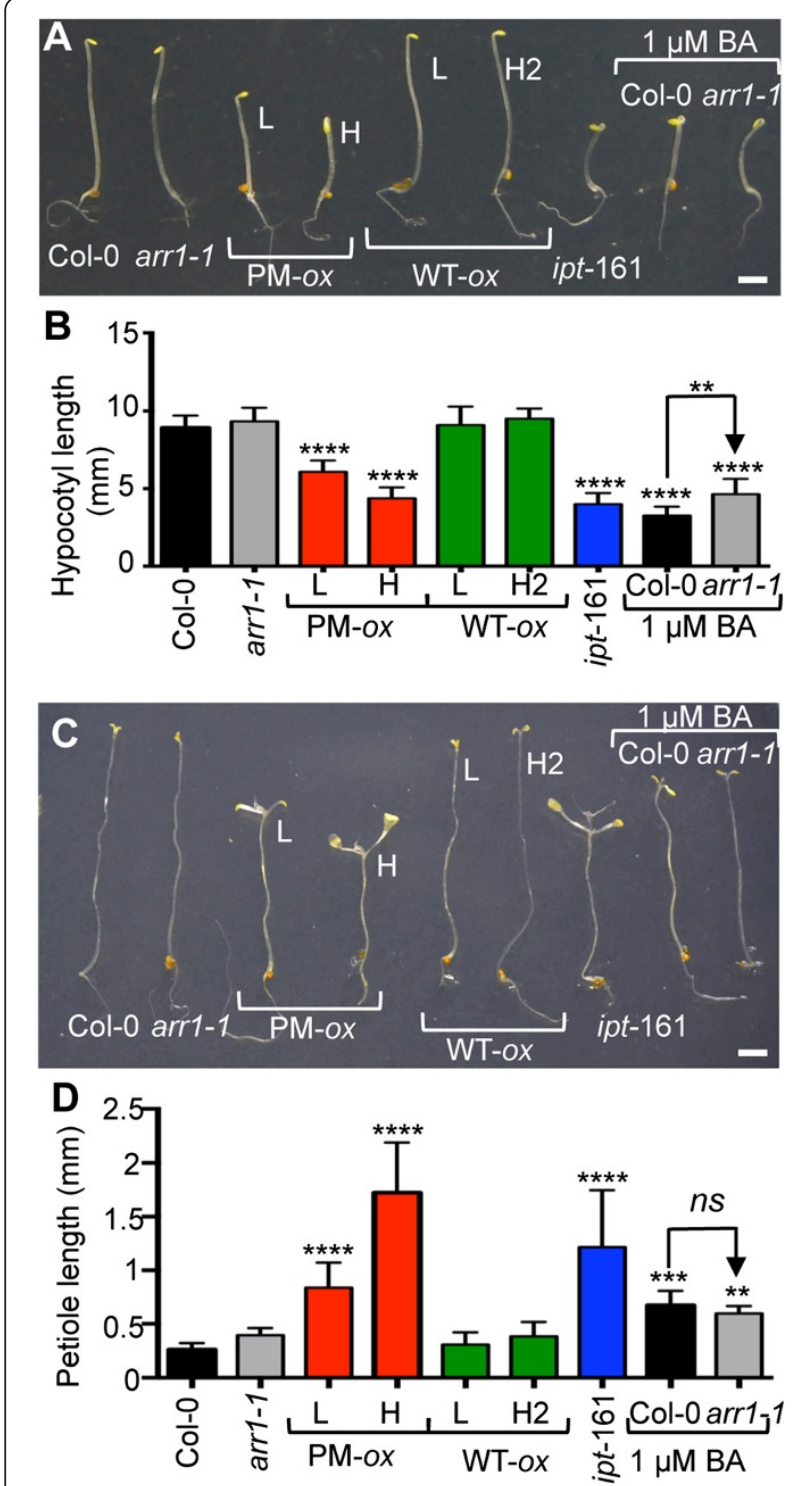

Figure 5 Constitutive cytokinin responses of etiolated seedlings expressing phosphomimic ARR1. (A) Four-day-old 35S: ARR1 overexpressing (WT-ox) and 35S:ARR $1^{\text {D94E }}$ overexpressing (PM-ox) etiolated seedlings are shown. Scale bar $=2 \mathrm{~mm}$. (B) Hypocotyl length of four-day-old seedlings was measured from photographs using ImageJ and is presented as mean \pm SD $(n \geq 20)$. Unless marked differently, lines were compared to Col-0 using a one-way ANOVA with Tukey's multiple comparison test. ${ }^{* *}, P<0.01$ and ${ }^{* * *}, P<0.0001$.

(C) Four-week-old etiolated seedlings. Scale bar $=2 \mathrm{~mm}$. (D) The length of the cotyledonary petioles was measured from photographs using ImageJ and presented as mean \pm SD $(n \geq 12)$. ${ }^{* *}, P<0.01$, ${ }^{* * *}, P<0.001$ and ${ }^{* * *}, P<0.0001$ for one-way ANOVA with Tukey's multiple comparison test. $n s$, not statistically significant $(P>0.05)$.

level. It was shown earlier that overexpression of the unmodified ARR1 form promotes a hypersensitive cytokinin response in tissue culture and leads to the formation of green callus even in the absence of exogenous cytokinin [18]. By comparing the effects of similarly expressed wild- type and phosphomimic ARR1, we show that ARR1 ${ }^{\mathrm{D} 94 \mathrm{E}}$ is much more potent at promoting this type of cytokininindependent tissue culture response.

Cytokinin treatments have been shown to increase the transcript levels of a number of genes encoding flavonoid biosynthetic enzymes [59]. Some of the flavonoid biosynthetic genes (e.g., chalcone synthase $(\mathrm{CHS}$ ) gene encoding the key enzyme of the flavonoid biosynthesis pathway CHS $[60,61]$ or dihydroflavonol reductase genes) were transcriptionally induced by BA, whereas the steady-state mRNA levels of others (e.g., chalcone isomerase) were increased via a post-transcriptional mechanism [59]. In agreement with the described effects of cytokinins on anthocyanin production, we found that anthocyanins accumulated to a higher level in 35S:ARR $1^{D 94 E}$ seedlings compared to the 35S:ARR1 lines, wild type and the arr1-1 mutant, which contained statistically identical amounts of anthocyanins (Figure 7A). These increases were approximately of the same magnitude as those measured in ipt-161 seedlings or in Col-0 treated with $1 \mu \mathrm{M}$ BA. The 35S:ARR $1^{D 94 E}(\mathrm{H})$ plants accumulated more anthocyanins than the $35 S: A R R 1^{D 94 E}(\mathrm{~L})$ plants, confirming that the transgene promotes cytokinin responses in a dose-dependent manner. The CHS level was increased only in the 35S:ARR1 ${ }^{D 94 E}(\mathrm{H})$ and ipt-161 seedlings which was in agreement with the high anthocyanin content of these lines (Figure 7A, B).

Cytokinins are known to inhibit leaf senescence and its hallmark symptom, chlorophyll breakdown [62-64]. It has been reported that artificially-induced chlorophyll loss caused by the incubation of detached leaves in darkness and senescence-induced chlorophyll loss are both mediated by the same mechanism [65]. To determine senescence progression under controlled conditions, we performed detached-leaf senescence tests and used cotyledons that are developmentally of the same age in the wild type and transgenic lines. We observed a significant senescence delay in both the 35S:ARR1 $1^{D 4 E}$ and ipt-161 lines when compared to the wild type and arr1-1 mutant (Figure 7C, D). For all three lines, the senescence delay was especially clear from days 5 to 7 into the treatment (Figure 7C, D). However, for this cytokinin-response, we observed no correlation between the strength of the cytokinin phenotype and the ARR $1^{\mathrm{D} 94 \mathrm{E}}$ expression level: in contrast to the other analyzed cytokinin responses where the 35S:ARR1 ${ }^{D 94 E}$ (L) line consistently had the weaker cytokinin phenotype, the $35 S: A R R 1^{D 94 E}$ (L) line showed the strongest senescence delay (Figure 7C, D). No changes in senescence-induced chlorophyll loss were observed in any of the wild-type ARR1 overexpressing lines or in the arr1-1 mutant.

Finally, it has been shown that cytokinins have a role in the regulation of meristem development [66]. Decrease in cytokinin sensitivity or content causes a decrease in shoot 


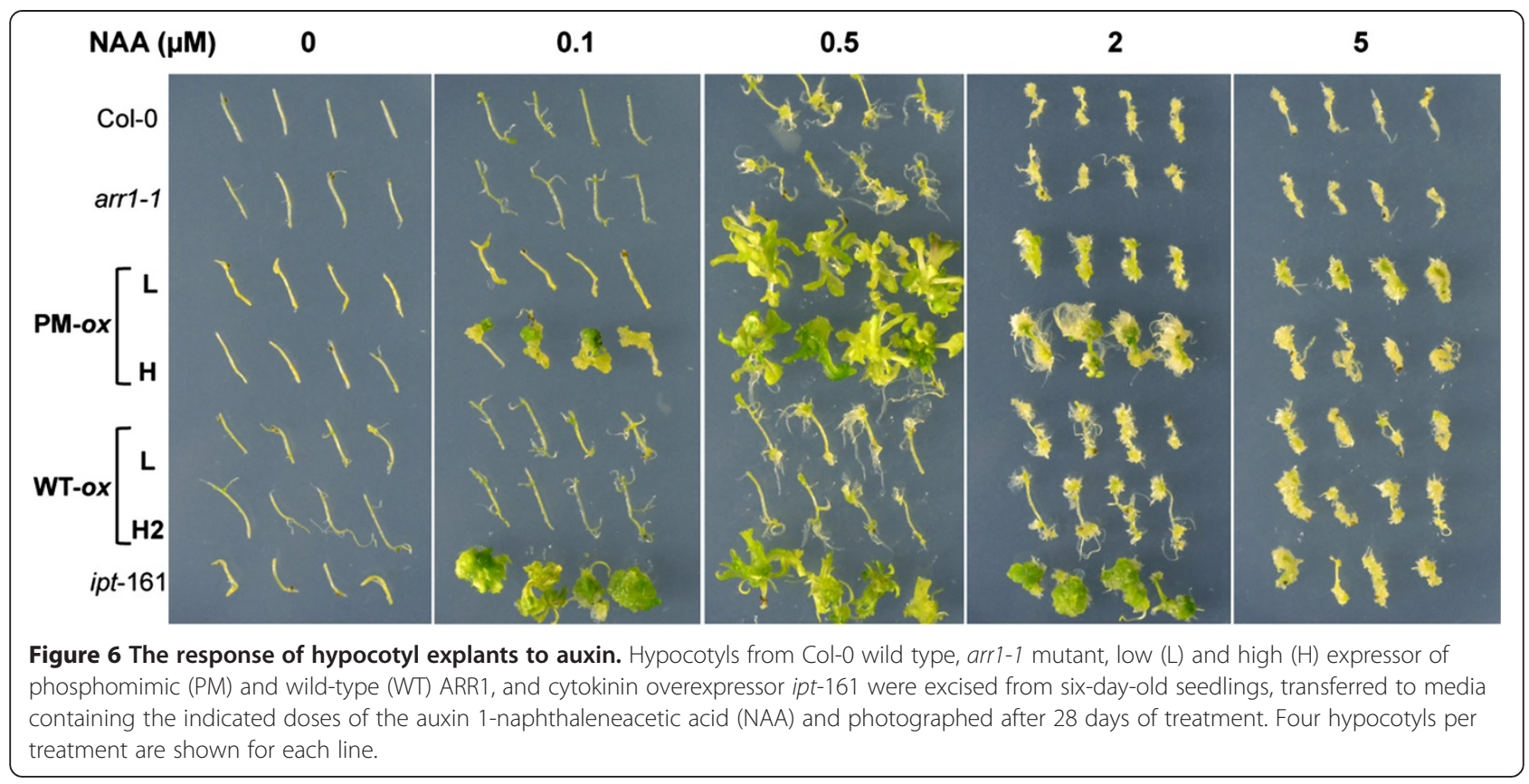

apical meristem (SAM) size, whereas increased cytokinin action promotes a SAM size increase [31,32,67-70]. Analyses of six-day-old seedlings revealed a significant SAM size increase in the 35S:ARR1 $1^{D 4 E}(\mathrm{H})$ line and in ipt-161 seedlings (Figure 7E). No changes of the SAM size were detected in seedlings overexpressing wild-type ARR1 or in the arr1-1 mutant (Figure 7E). On the other hand, a decrease in cytokinin sensitivity or content was shown previously to promote an increase in root apical meristem (RAM) size, whereas increased cytokinin action promoted a RAM size decrease [71-73]. Consistent with their increased cytokinin action, we observed a decrease in RAM size in both $35 S: A R R 1^{D 94 E}$ lines, while the ARR1 overexpressing lines did not significantly differ from the wild type (Figure 7F). In agreement with the previous reports [72], we observed an increase in RAM size in the arr1-1 seedlings (Figure 7F). Collectively, these analyses confirmed the constitutive cytokinin response phenotype of the 35S: $A R R 1^{D 94 E}$ lines.

\section{Ethylene-dependent constitutive cytokinin responses in 35S:ARR1 ${ }^{\text {D94E }}$ overexpressing lines}

Some of the effects of cytokinin on plant development are mediated by increased ethylene biosynthesis that is caused by the stabilization and thus increased activity of the key ethylene biosynthesis enzyme ACC synthase $[56,74,75]$. In dark-grown seedlings, cytokinin promotes a triple response that includes an increase in apical hook curvature and an inhibition in both hypocotyl and root elongation [56]. In light-grown seedlings, the inhibitory effect of cytokinin on root elongation is also in part mediated by increased ethylene production [74].
To test if the reduced hypocotyl elongation in dark-grown 35S:ARR1 $1^{D 94 E}$ seedlings is a result of increased ethylene action, we introgressed the $35 S: A R R 1^{D 94 E}(\mathrm{H})$ line into the ethylene insensitive mutant ein2-1 that carries a defect in a key step of the ethylene response pathway [76]. In lightgrown seedlings, loss of EIN2 function partially suppressed the short-root phenotype of the $35 S: A R R 1^{D 94 E}(\mathrm{H})$ seedlings (Figure 8A, B). In contrast, ein2-1 completely suppressed the short-hypocotyl phenotype of etiolated 35S:ARR $1^{D 94 E}(\mathrm{H})$ seedlings (Figure $\left.8 \mathrm{C}, \mathrm{D}\right)$ ). A significant portion of the inhibitory effect of cytokinins on the root and hypocotyl elongation growth of young seedlings is mediated through an increase in ethylene action caused by a cytokinin-induced increase in ethylene biosynthesis [75]. It was shown earlier that this cytokinin-induced ethylene biosynthesis involves the primary cytokinin response pathway [77]. Our results confirm this order of events by showing that the inhibitory effects of increased ARR1 action on elongation growth is suppressed in an ethylene insensitive background. However, whereas the suppression of hypocotyl growth inhibition was complete in etiolated seedlings, we observed only a partial reversion of root elongation growth in light-grown seedlings. Considering that the ein2-1 mutation causes a near complete ethylene resistance [78], it is unlikely that the partial reversion in light-grown seedlings is caused by residual ethylene action. Instead, cytokinin action probably controls root elongation via an ethylene-independent pathway. Indeed, it was shown earlier that cytokinin regulates root growth by controlling the distribution of auxin that impacts the activity and size of the root meristem [79]. 

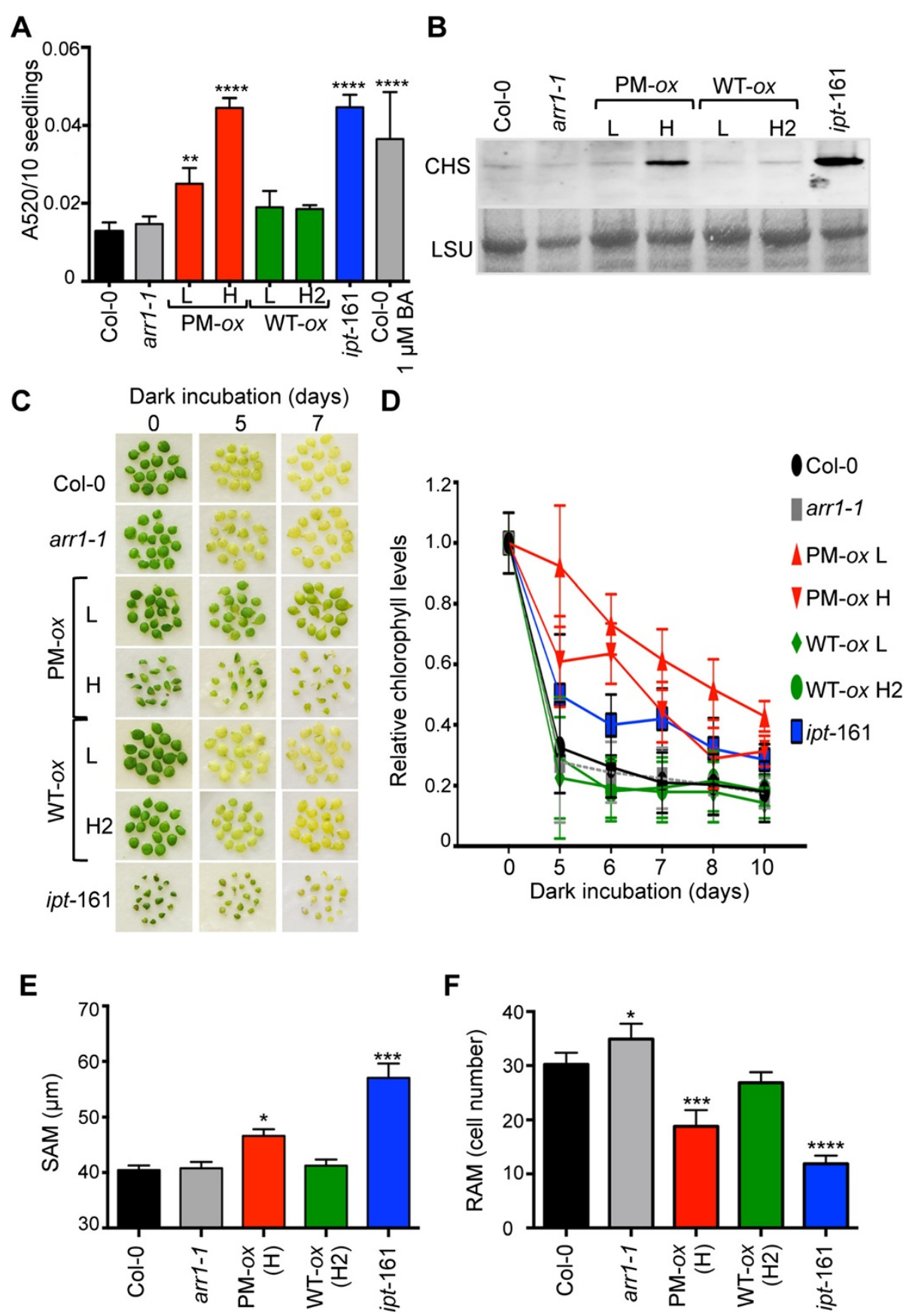

Figure 7 Constitutive cytokinin responses of 35S:ARR $1^{D 94}$ (PM-ox) lines in anthocyanin accumulation, the timing of senescence and meristem size. (A) The anthocyanin content, expressed as absorbance value at $520 \mathrm{~nm}$ per 10 seedlings, was measured in six-day-old seedlings. The mean \pm SD of three biological replicates is shown. Col-0 was treated with BA for 16 hours. One-way ANOVA with Tukey's test was used to analyze the data. ${ }^{* *}, P<0.01 ;{ }^{* * *}, P<0.0001$. (B) Immunoblotting analyses of chalcone synthase (CHS) levels in eight-day-old seedlings.

(C) Delayed senescence in PM-ox plants. Seedlings of the wild type, arr1-1, PM-ox, WT-ox and ipt-161 lines were grown on MS/2 media for 5 days, and then used to dissect cotyledons. Cotyledons were placed on moistened filter papers in petri dishes, and transferred to darkness. Photographs were taken at the indicated times. (D) Relative chlorophyll levels in cotyledons incubated in the dark for the indicated times. Chlorophyll content at day one for each line was assigned the value of 1. Mean \pm SD of two independent samples (with 15 cotyledons each) is shown. (E) Analyses of the shoot apical meristem (SAM) size in six-day-old seedlings. SAM diameters measured from photomicrographs are presented as mean \pm SEM $(n=25)$. Results were compared to Col-0 using a one-way ANOVA with Tukey's test.*, $P<0.05$; ${ }^{* * *}, P<0.001$. (F) Size of the root apical meristem (RAM) was analyzed in seven-day-old seedlings grown on vertically positioned plates. The number of RAM cortex cells measured from photomicrographs is presented as mean \pm SEM $(n=25)$. Significance of the difference with Col-0 is shown. ${ }^{*}, P<0.05 ;{ }^{* *}, P<0.01$ (one-way ANOVA with Tukey's test). 


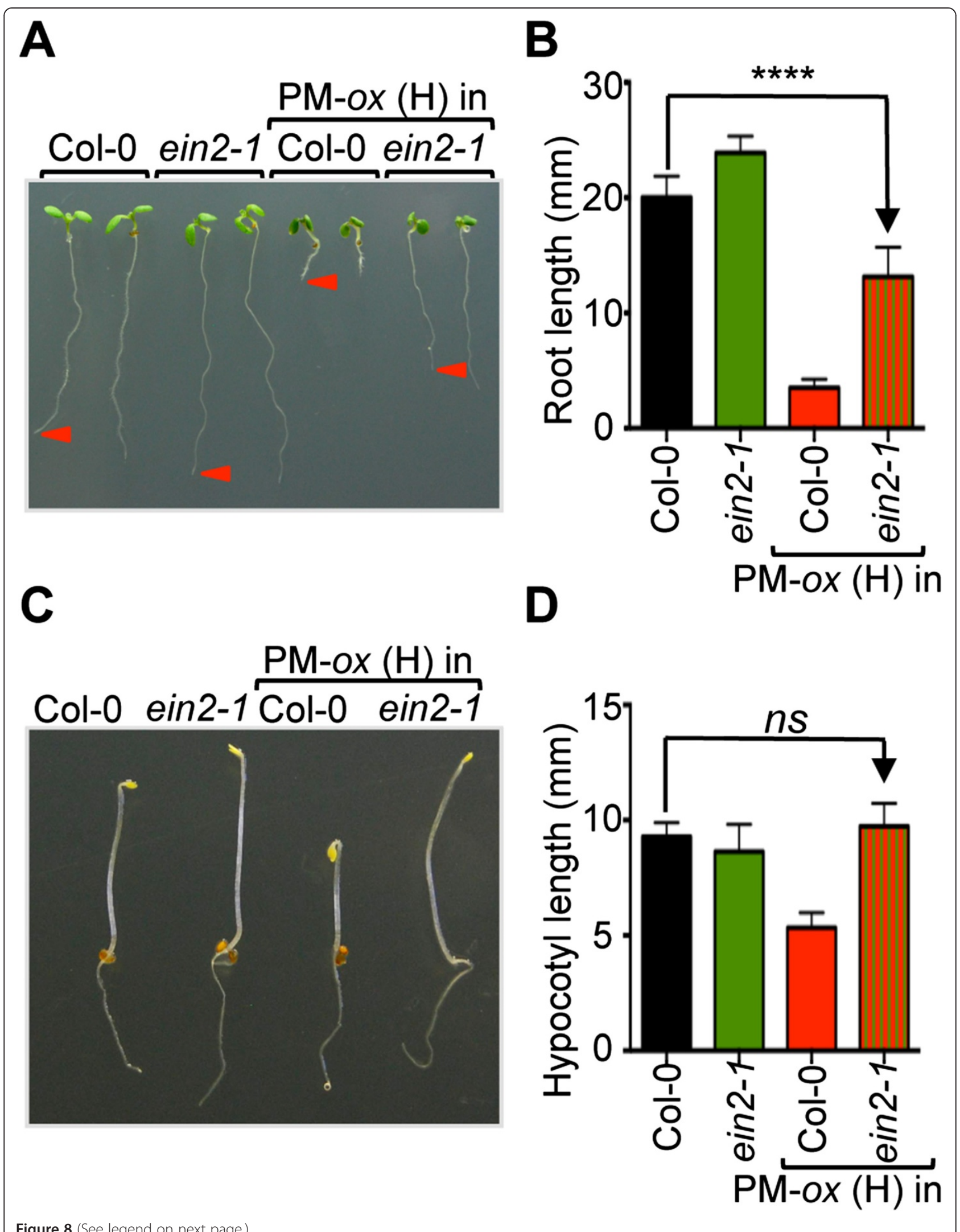

Figure $\mathbf{8}$ (See legend on next page.) 
(See figure on previous page.)

Figure 8 Ethylene-dependent constitutive cytokinin responses in 35S:ARR1 ${ }^{\text {D94E }}$ (PM-ox) seedlings. (A) Representative seven-day-old Col-0, ein2-1, PM-ox (H) and PM-ox (H) ein2-1 plants grown on vertical MS/2 plates. (B) Root length of seven-day-old seedlings was measured from photographs. Data are presented as mean \pm SD $(n=20)$. One-way ANOVA with Tukey's multiple comparison test was used to analyze the statistical significance of the results. Only the significance of the difference between Col-0 and PM-ox (H) ein2-1 is shown. ${ }^{* * * *}, P<0.0001$. (C) Representative four-day-old seedlings germinated and grown in darkness on MS/2 medium. (D) Hypocotyl length of four-day-old etiolated seedlings. Data are presented as mean \pm SD $(n=20)$. Only the significance of the difference between Col- 0 and PM-ox $(H)$ ein2-1 is shown. ns, not significant (one-way ANOVA with Tukey's multiple comparison test).

Our results with $35 S: A R R 1^{D 94 E}$ stand in contrast to results obtained with plants expressing 35S:ARR2 $2^{804 E}$, the phosphomimic version of ARR2 [51]. In this earlier study, it was concluded that ARR2 plays a role in the ethylene response pathway because the constitutive triple response phenotype of seedlings expressing 35S: $A R R 2^{804 E}$ was not suppressed by ethylene biosynthesis inhibition [51]. In contrast, our observation that the etiolated phenotype of 35S:ARR1 $1^{D 94 E}$ seedlings is fully suppressed by loss of function of the EIN2 ethylene signaling component (Figure 8), indicated that the constitutive triple response of $35 S: A R R 1^{D 94 E}$ seedlings is caused by an increase in ethylene biosynthesis which is in agreement with the well-established stimulatory role of cytokinin on ACC synthase activity $[56,74,75]$. Taken together, this may be yet another example suggesting that ARR2 has a specific function in comparison to other RRBs such as ARR1 [41,42,51,80,81].

\section{Developmental changes in adult 35S:ARR1 ${ }^{\text {D94E }}$ plants} Both the 35S:ARR1 $1^{D 94 E}$ and ipt-161 plants remained smaller than the wild type during the early stages of adult development (Figure 9A, B). However, after 44 days of growth, the rosette size of the 35S:ARR1 ${ }^{D 94 E}(\mathrm{~L})$ plants was increased compared to the wild type and arr1-1 (Figure 9A, B). These larger rosettes were also visibly greener which was in agreement with the senescence delay observed with the cotyledon assay (Figure 7C, D). The ARR1 overexpressing lines and arr1-1 mutant had wild-type sized rosettes. The ipt-161 plants, which required a longer growth period to reach their final size, remained substantially smaller after prolonged growth on soil (Figure 9A, B).

Cytokinins are known to be involved in the regulation of shoot branching. Although the hormonal regulation of shoot branching has been discovered many decades ago, new hormones that influence this process and the identities of the effectors involved are still being discovered [82-86]. Because cytokinins increase the size of shoot apical meristems, and because they are known to promote the release of apical dominance when directly applied to lateral buds, it is commonly believed that cytokinins increase shoot branching $[67,82,87]$. However, the inflorescences of $35 S: A R R 1^{D 94 E}$ plants were not visibly more branched than inflorescences of the wild type or arr1-1 (Figure 9C). The length of the primary inflorescence stem was significantly increased in the 35S: $A R R 1^{D 94 E}(\mathrm{~L})$ line (Figure 9C, D), which is a likely consequence of the delayed senescence phenotype observed in these plants (Figures 7C, D and 9A, B). The inflorescence of ipt-161 plants was substantially shorter and not more branched compared all other lines (Figure 9C, D), which is in agreement with what was reported earlier for the C24 ecotype version of this transgenic line [53]. One unexpected feature of the 35S:ARR1 ${ }^{D 94 E}$ inflorescence phenotype was the absence of any visible increase in branching accompanied by a loss in shoot apical dominance. Considering the classical role of cytokinins in promoting release of apical dominance [5,67,82,87], one would expect that increased cytokinin action would lead to a bushier inflorescence structure. However, recent studies have shown that the down-regulation of cytokinin biosynthesis and suppression of RRBs function increase inflorescence branching $[88,89]$. These studies combined with our data suggest that cytokinins play a more complex role in this developmental process. However, it also remains possible that the effect of the 35S:ARR1 $1^{D 94 E}$ transgene is suppressed at this later developmental stage and that we therefore did not observe any effects on inflorescence development.

\section{Conclusions}

Here we show that seedlings ectopically expressing a phosphomimic version of ARR1 resembled the cytokinintreated wild type, and that the relative strengths of most of the cytokinin-related phenotypes correlated with ARR1 D94E abundance. Furthermore, we showed that the constitutive cytokinin response phenotype, which was not observed in ARR1 overexpressing plants, is the result of a significant increase in the capacity to promote cytokinin responses in the absence of exogenous cytokinin application.

Because we used the constitutive CaMV $35 \mathrm{~S}$ promoter, our results do not interpret the function of the ARR1 gene in Arabidopsis development. Rather, they enable us to reach two important conclusions about the ARR1 protein. First, because the phosphomimic substitution constitutively activated the cytokinin response both at the molecular, physiological and developmental levels, we concluded that ARR1 phosphorylation at D94 is indeed a key step in cytokinin signaling. The D94E substitution 


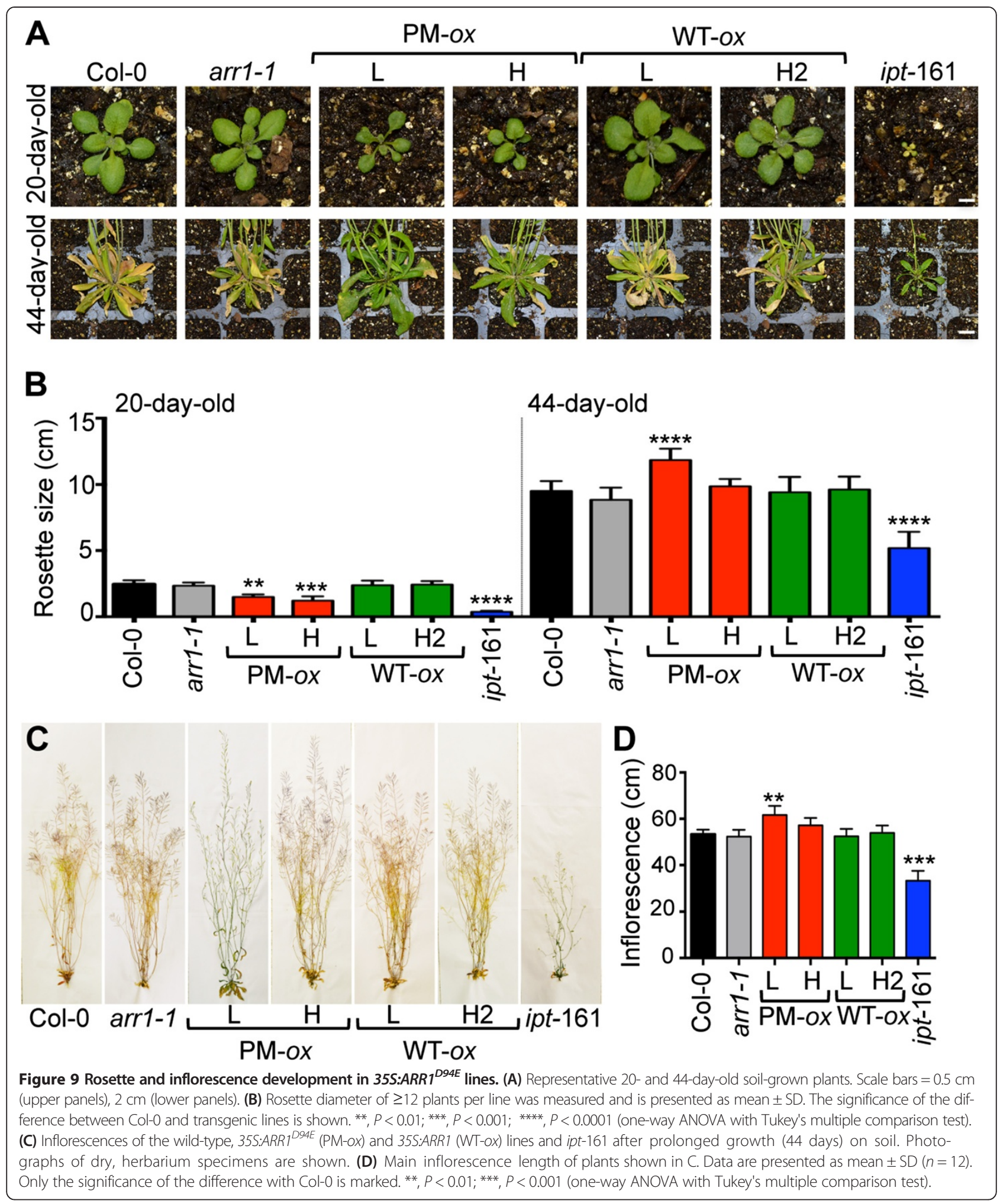

converted ARR1 from a latent into an active transcription factor which is 100 -fold more potent as a response activator compared to its wild-type counterpart. The second conclusion is that phosphomimic (and presumably phosphorylated) ARR1 has the capacity to promote most of the currently known cytokinin responses. However, it remains possible that ARR1 ${ }^{\mathrm{D} 94 \mathrm{E}}$ does not promote cytokinin responses that were not analyzed in this study. 
Our results show that the $35 S: A R R 1^{D 94 E}$ transgene mimics the effects of cytokinin treatments, and hence, validate the current model of cytokinin signaling which stresses the essential role for phosphorylation of RRBs on their conserved aspartate residue in promoting a wide-spectrum of cytokinin responses. Whereas our results provide information about the ARR1 protein and the cytokinin response pathway in general, the observation that a phosphomimic version of ARR1 can be used as a wide-spectrum cytokinin response activator is also relevant for biotechnology and agriculture. Cytokinins regulate a number of developmental processes and environmental responses that are of significance for crop yields [90,91]. So far, the engineering of cytokinincontrolled agriculturally important traits has focused predominantly on modifying cytokinin accumulation either via changes in biosynthesis or metabolism [90]. An alternative approach could be the use of constitutively active signaling proteins in combination with tissue or developmental stage specific promoters. Based on the high level of conservation of the cytokinin response pathway in higher plant species [92], it is reasonable to assume that phosphomimic versions of the corresponding ARR1 versions of crop species will be useful for the engineering of cytokinin-related traits.

\section{Methods}

\section{Plant material and growth conditions}

For all experiments, Arabidopsis thaliana wild-type, transgenic and mutant plants (all in Col-0 background) were germinated and grown under sterile conditions. Surfacesterilized seeds were stratified for two days and plated on half-strength Murashige and Skoog medium (MS/2; 0.5x Murashige and Skoog salts with $1 \%$ sucrose, $\mathrm{pH}$ 5.7). Plants were grown in a growth chamber at $22^{\circ} \mathrm{C}$ under a $16 \mathrm{hr}$ light $\left(80 \mu \mathrm{mol} \mathrm{m} \mathrm{m}^{-2} \mathrm{~s}^{-1}\right) / 8 \mathrm{hr}$ dark cycle. For growth on soil, sterile seedlings were transferred to a 1:1 mix of Potting Mix soil (Fertilome) and Vermiculite Perlite (Therm-o-Rock East Inc.). The arr1-1 and ein2-1 mutants and the IPT:ipt transgenic line ipt-161 in Col-0 background were described previously $[18,28,78]$.

To generate wild-type and phosphomimic ARR1 overexpressing plants, the ARR1 (ARR1; At3g16857) cDNA was PCR-amplified from an Arabidopsis cDNA library using attB primers, and cloned into pDONR221 using BP clonase enzyme mix (Invitrogen). The resulting pENTR$A R R 1$ clone was used for site-directed mutagenesis with forward and reverse primers 5'-GATGTTCAT ATGCCT GAGATGGACGGTTTCAAG-3' that introduce the Cto-G mutation, and thus $\mathrm{D}$ to $\mathrm{E}$ substitution at position 94. The wild-type and the $A R R 1^{\mathrm{D} 94 \mathrm{E}}$ fragment were recombined into the pEarlyGate100 binary vector [93] using LR clonase enzyme mix (Invitrogen). The construct were introduced into the C58C1Rif Agrobacterium tumefaciens strain which was used for floral dip transformation [94]. Transgenic plants were selected on solid MS/2 medium containing $1 \%$ sucrose and $10 \mu \mathrm{g} / \mathrm{ml}$ phosphinothricin (GoldBio).

\section{Protein isolation and immunoblotting analyses}

For immunoblotting, total proteins were isolated in $2 \mathrm{X}$ SDS-PAGE loading buffer, separated by SDS-PAGE, and transferred to nitrocellulose membranes as described [95]. Commercial antibodies used were monoclonal anti- $\alpha$ tubulin antibody (dilution 1:10,000; clone B-5-1-2, Sigma) and anti-chalcone synthase antibody (dilution 1:1000; Santa Cruz Biotechnology). To generate ARR1-specific antibodies, a 55 amino acid-long peptide (amino acids 348 to 402) was chosen as an antigen. This peptide has $47 \%$ amino acid sequence identity with ARR1 homologue ARR2. The longest consecutive stretch of identical amino acids in this region of ARR1 and ARR2 is six. The antisera were generated in rabbits, and affinity purified against the antigen before use (Strategic Diagnostics). The affinity-purified antiserum was used after 1:10,000 dilution. Signals were captured using ChemiDoc XRS, and the signal intensity was determined using Quantity One software (Bio-Rad).

\section{Cytokinin response assays \\ Inhibition of root elongation}

Vertically grown seedlings were transferred to control $\mathrm{MS} / 2$ plates and MS/2 plates containing benzyladenine (BA), and the initial root length was marked. Seedlings were grown vertically for an additional 7 days. Root lengths were measured using ImageJ (http://rsb.info.nih.gov/ij/).

\section{Induction of cytokinin-responsive genes}

RNA was isolated using the TRIzol reagent (Invitrogen) from plants grown in liquid MS/2 media for 7 days. The qRT-PCR analyses and the sequence of ARR5 primers was described [28]. Primers used for the analyses of EXP1 levels were 5'-CAACGCATCGCTCAATACAG-3' and 5'-CTCCGACGTTAGTGATCAGAAC-3'.

\section{Callus and shoot induction in root and hypocotyls explants}

Hypocotyls of plants grown in darkness for four days and then in light for two days were excised and transferred to full-strength MS media supplemented with $2 \%$ sucrose and naphthalene-1-acetic acid (NAA). A minimum of 40 hypocotyls per line was tested for each NAA concentration. Test plates were kept in a controlled environment chamber with continuous light and temperature of $22^{\circ} \mathrm{C}$, and were followed daily.

\section{Anthocyanin accumulation}

Seedlings grown for six days on MS/2 media were collected (10 per sample), submerged into $500 \mu \mathrm{l}$ of acid methanol $(1 \% \mathrm{HCl})$, and rocked at $4{ }^{\circ} \mathrm{C}$ for 12 hours in 
darkness. The anthocyanin fraction was extracted using chloroform phase separation as described [60]. The anthocyanin content was measured a DTX 880 Multimode Detector (Beckman Coulter) with a 520/8 nm absorbance filter.

\section{Cotyledon senescence}

Cotyledons of five-day-old light-grown seedlings were excised and transferred to Petri dishes with a filter paper moistened with distilled water. Samples were incubated in the dark. At the denoted time intervals, cotyledons were photographed and a minimum of 15 cotyledons per line was frozen in liquid nitrogen for chlorophyll extraction. For chlorophyll extraction, frozen cotyledons were incubated with $80 \%(\mathrm{v} / \mathrm{v})$ acetone at $4^{\circ} \mathrm{C}$ for 12 hours in the darkness. Absorbance at 647 and $664 \mathrm{~nm}$ was measured using Ultrospec 2000 (Pharmacia), and the chlorophyll amount was calculated according to Graan and Ort [96].

\section{SAM size measurements}

Shoot apical meristem size was analyzed as described [97]. Briefly, six-day-old seedlings were cleared with Hoyer's solution for 24 to 48 hours. Slides were observed with the Zeiss Axioplan2 and Axiovision software using the $40 \times$ objective/ $1 \times$ optivar.

\section{Root meristem cell number measurements}

Root meristem size was analyzed as described [98]. Briefly, seven-day-old seedlings grown on vertical plates were cleared with Hoyer's solution for 12 hours, mounted on slides using Hoyer's solution and observed with the Olympus BX51 microscope (40× objective) equipped with a differential interference contrast technology and a DP70 digital camera.

\section{Biometrics}

The descriptive statistics, plotting, and statistic analyses were done using Prism 6 (GraphPad). The statistical tests used to analyze the data, the size of tested sample sets and number of biological replicates are stated in the Result and Discussion section or Figure legends.

\section{Competing interests}

The authors declare that there are no competing financial interests.

\section{Authors' contributions}

JK and JAS devised the experimental setup, performed most of the experiments and analyses, and wrote the manuscript. YL conducted the qPCR analyses, analyzed the anthocyanin and CHS levels. SEP analyzed the SAM size. YL and SEP participated in manuscript editing. All authors have approved the manuscript.

\section{Acknowledgements}

This work was supported by grants from NIFA/NRI (2005-35304-16043), NIFA/ HATCH (KY006073) NSF (0919991) and Kentucky Tobacco Research and Development Center. We thank Atsuhiro Oka for providing the arr1-1 mutant line and the $\mathrm{ABRC}$ (Columbus, OH) for the ein2-1 mutant and the ipt-161 transgenic line in C24 background.

\section{Author details}

${ }^{1}$ The Rockefeller University, 1230 York Avenue, New York, NY 10065, USA. ${ }^{2}$ Plant Physiology, Biochemistry, Molecular Biology Program, Department of Plant and Soil Sciences, University of Kentucky, 1401 University Drive, Lexington, KY 40546, USA.

Received: 2 September 2013 Accepted: 9 January 2014

Published: 14 January 2014

\section{References}

1. Mok DW, Mok MC: Cytokinin metabolism and action. Annu Rev Plant Physiol Plant Mol Biol 2001, 52:89-118.

2. Kiba T, Sakakibara H: Role of cytokinin in the regulation of plant development. In Plant Developmental Biology - Biotechnological Perspectives. 2nd edition. Edited by Davey E-CPaMR. Berlin Heidelberg: Springer-Verlag; 2010:237-254.

3. Argueso CT, Ferreira FJ, Kieber JJ: Environmental perception avenues: the interaction of cytokinin and environmental response pathways. Plant Cell Environ 2009, 32:1147-1160.

4. Werner T, Schmülling T: Cytokinin action in plant development. Curr Opin Plant Biol 2009, 12:527-538.

5. Durbak A, Yao H, McSteen P: Hormone signaling in plant development. Curr Opin Plant Biol 2012, 15:92-96.

6. Hwang I, Sheen J: Two-component circuitry in Arabidopsis cytokinin signal transduction. Nature 2001, 413:383-389.

7. Hutchison CE, Kieber JJ: Cytokinin signaling in Arabidopsis. Plant Cell 2002, 14(Suppl):S47-S59.

8. Müller B, Sheen J: Arabidopsis cytokinin signaling pathway. Sci STKE 2007, 2007:cm5.

9. Hwang I, Chen HC, Sheen J: Two-component signal transduction pathways in Arabidopsis. Plant Physiol 2002, 129:500-515.

10. Heyl A, Brault M, Frugier F, Kuderova A, Lindner AC, Motyka V, Rashotte AM, Schwartzenberg KV, Vankova R, Schaller GE: Nomenclature for members of the two-component signaling pathway of plants. Plant Physiol 2013, 161:1063-1065.

11. Inoue T, Higuchi M, Hashimoto Y, Seki M, Kobayashi M, Kato T, Tabata S, Shinozaki K, Kakimoto T: Identification of CRE1 as a cytokinin receptor from Arabidopsis. Nature 2001, 409:1060-1063.

12. Suzuki T, Miwa K, Ishikawa K, Yamada H, Aiba H, Mizuno T: The Arabidopsis sensor His-kinase, AHK4, can respond to cytokinins. Plant Cell Physiol 2001, 42:107-113.

13. Yamada H, Suzuki T, Terada K, Takei K, Ishikawa K, Miwa K, Yamashino T, Mizuno T: The Arabidopsis AHK4 histidine kinase is a cytokinin-binding receptor that transduces cytokinin signals across the membrane. Plant Cell Physiol 2001, 42:1017-1023.

14. Miwa K, Ishikawa K, Terada K, Yamada H, Suzuki T, Yamashino T, Mizuno T: Identification of amino acid substitutions that render the Arabidopsis cytokinin receptor histidine kinase AHK4 constitutively active. Plant Cell Physiol 2007, 48:1809-1814.

15. Miyata S, Urao T, Yamaguchi-Shinozaki K, Shinozaki K: Characterization of genes for two-component phosphorelay mediators with a single HPt domain in Arabidopsis thaliana. FEBS Lett 1998, 437:11-14.

16. Hutchison CE, Li J, Argueso C, Gonzalez M, Lee E, Lewis MW, Maxwell BB, Perdue TD, Schaller GE, Alonso JM, et al: The Arabidopsis histidine phosphotransfer proteins are redundant positive regulators of cytokinin signaling. Plant Cell 2006, 18:3073-3087.

17. Suzuki T, Ishikawa K, Yamashino T, Mizuno T: An Arabidopsis histidinecontaining phosphotransfer (HPt) factor implicated in phosphorelay signal transduction: overexpression of AHP2 in plants results in hypersensitiveness to cytokinin. Plant Cell Physiol 2002, 43:123-129.

18. Sakai H, Honma T, Aoyama T, Sato S, Kato T, Tabata S, Oka A: ARR1, a transcription factor for genes immediately responsive to cytokinins. Science 2001, 294:1519-1521.

19. Mason MG, Li J, Mathews DE, Kieber JJ, Schaller GE: Type-B response regulators display overlapping expression patterns in Arabidopsis. Plant Physiol 2004, 135:927-937.

20. Sheen J: Phosphorelay and transcription control in cytokinin signal transduction. Science 2002, 296:1650-1652. 
21. D'Agostino I, Deruère J, Kieber J: Characterization of the response of the Arabidopsis ARR gene family to cytokinin. Plant Physiol 2000, 124:1706-1717.

22. Taniguchi M, Sasaki N, Tsuge T, Aoyama T, Oka A: ARR1 directly activates cytokinin response genes that encode proteins with diverse regulatory functions. Plant Cell Physiol 2007, 48:263-277.

23. Ishida K, Yamashino T, Yokoyama A, Mizuno T: Three type-B response regulators, ARR1, ARR10 and ARR12, play essential but redundant roles in cytokinin signal transduction throughout the life cycle of Arabidopsis thaliana. Plant Cell Physiol 2008, 49:47-57.

24. To JPC, Deruere J, Maxwell BB, Morris VF, Hutchison CE, Ferreira FJ, Schaller $\mathrm{GE}$, Kieber JJ: Cytokinin regulates type-A Arabidopsis response regulator activity and protein stability via two-component phosphorelay. Plant Cell 2007, 19:3901-3914.

25. Kakimoto T: Perception and signal transduction of cytokinins. Annu Rev Plant Biol 2003, 54:605-627.

26. Argueso CT, Raines $T$, Kieber JJ: Cytokinin signaling and transcriptional networks. Curr Opin Plant Biol 2010, 13:533-539.

27. Mähönen AP, Bishopp A, Higuchi M, Nieminen KM, Kinoshita K, Törmäkangas K, Ikeda Y, Oka A, Kakimoto T, Helariutta Y: Cytokinin signaling and its inhibitor AHP6 regulate cell fate during vascular development. Science 2006, 311:94-98.

28. Li Y, Kurepa J, Smalle J: AXR1 promotes the Arabidopsis cytokinin response by facilitating ARR5 proteolysis. Plant J 2013, 74:13-24.

29. Chevalier F, Perazza D, Laporte F, Le Hénaff G, Hornitschek P, Bonneville J-M Herzog M, Vachon G: GeBP and GeBP-like proteins are noncanonical leucine-zipper transcription factors that regulate cytokinin response in Arabidopsis. Plant Physiol 2008, 146:1142-1154.

30. Rashotte AM, Mason MG, Hutchison CE, Ferreira FJ, Schaller GE, Kieber JJ: A subset of Arabidopsis AP2 transcription factors mediates cytokinin responses in concert with a two-component pathway. Proc Natl Acad SCi US A 2006, 103:11081-11085.

31. Higuchi M, Pischke MS, Mähönen AP, Miyawaki K, Hashimoto Y, Seki M, Kobayashi M, Shinozaki K, Kato T, Tabata S, et al: In planta functions of the Arabidopsis cytokinin receptor family. Proc Natl Acad Sci U S A 2004, 101:8821-8826.

32. Nishimura C, Ohashi Y, Sato S, Kato T, Tabata S, Ueguchi C: Histidine kinase homologs that act as cytokinin receptors possess overlapping functions in the regulation of shoot and root growth in Arabidopsis. Plant Cell 2004, 16:1365-1377.

33. Imamura A, Hanaki N, Nakamura A, Suzuki T, Taniguchi M, Kiba T, Ueguchi C, Sugiyama T, Mizuno T: Compilation and characterization of Arabidopsis thaliana response regulators implicated in His-Asp phosphorelay signal transduction. Plant Cell Physiol 1999, 40:733-742.

34. Brandstatter I, Kieber JJ: Two genes with similarity to bacterial response regulators are rapidly and specifically induced by cytokinin in Arabidopsis. Plant Cell 1998, 10:1009-1019.

35. Mason MG, Mathews DE, Argyros DA, Maxwell BB, Kieber JJ, Alonso JM, Ecker JR, Schaller GE: Multiple type-B response regulators mediate cytokinin signal transduction in Arabidopsis. Plant Cell 2005, 17:3007-3018.

36. Riefler M, Novak O, Strnad M, Schmülling T: Arabidopsis cytokinin receptor mutants reveal functions in shoot growth, leaf senescence, seed size, germination, root development, and cytokinin metabolism. Plant Cell 2006, 18:40-54.

37. Hradilová J, Brzobohatý B: Expression pattern of the AHP gene family from Arabidopsis thaliana and organ specific alternative splicing in AHP5 gene. Biol Plant 2007, 51:257-267.

38. Osakabe Y, Miyata S, Urao T, Seki M, Shinozaki K, Yamaguchi-Shinozaki K: Overexpression of Arabidopsis response regulators, ARR4/ATRR1/IBC7 and ARR8/ATRR3, alters cytokinin responses differentially in the shoot and in callus formation. Biochem Biophys Res Commun 2002, 293:806-815.

39. Tajima Y, Imamura A, Kiba T, Amano Y, Yamashino T, Mizuno T: Comparative studies on the type-B response regulators revealing their distinctive properties in the His-to-Asp phosphorelay signal transduction of Arabidopsis thaliana. Plant Cell Physiol 2004, 45:28-39.

40. Stolz A, Riefler M, Lomin SN, Achazi K, Romanov GA, Schmülling T: The specificity of cytokinin signalling in Arabidopsis thaliana is mediated by differing ligand affinities and expression profiles of the receptors. Plant J 2011. doi:10.1111/j.1365-313X.2011.04584.X.

41. Choi J, Huh SU, Kojima M, Sakakibara H, Paek KH, Hwang I: The cytokininactivated transcription factor ARR2 promotes plant immunity via TGA3/
NPR1-dependent salicylic acid signaling in Arabidopsis. Dev Cell 2010, 19:284-295.

42. Kim HJ, Ryu H, Hong SH, Woo HR, Lim PO, Lee IC, Sheen J, Nam HG, Hwang I: Cytokinin-mediated control of leaf longevity by AHK3 through phosphorylation of ARR2 in Arabidopsis. Proc Natl Acad Sci U S A 2006, 103:814-819.

43. Müller B: Generic signal-specific responses: cytokinin and contextdependent cellular responses. J Exp Bot 2011, 62:3273-3288.

44. Yokoyama A, Yamashino T, Amano Y-I, Tajima Y, Imamura A, Sakakibara H, Mizuno T: Type-B ARR transcription factors, ARR10 and ARR12, are implicated in cytokinin-mediated regulation of protoxylem differentiation in roots of Arabidopsis thaliana. Plant Cell Physiol 2007, 48:84-96.

45. Argyros RD, Mathews DE, Chiang $\mathrm{YH}$, Palmer CM, Thibault DM, Etheridge $\mathrm{N}$, Argyros DA, Mason MG, Kieber JJ, Schaller GE: Type B response regulators of Arabidopsis play key roles in cytokinin signaling and plant development. Plant Cell 2008, 20:2102-2116.

46. Lohrmann J, Sweere U, Zabaleta E, Bäurle I, Keitel C, Kozma-Bognar L, Brennicke A, Schäfer E, Kudla J, Harter K: The response regulator ARR2: a pollen-specific transcription factor involved in the expression of nuclear genes for components of mitochondrial complex I in Arabidopsis. Mol Genet Genomics 2001, 265:2-13.

47. Hill K, Mathews DE, Kim HJ, Street IH, Wildes SL, Chiang YH, Mason MG, Alonso JM, Ecker JR, Kieber JJ, et al: Functional characterization of type-B response regulators in the Arabidopsis cytokinin response. Plant Physiol 2013, 162:212-224

48. Klose KE, Weiss DS, Kustu S: Glutamate at the site of phosphorylation of nitrogen-regulatory protein NTRC mimics aspartyl-phosphate and activates the protein. $J$ Mol Biol 1993, 232:67-78.

49. Stock AM, Robinson VL, Goudreau PN: Two-component signal transduction. Annu Rev Biochem 2000, 69:183-215.

50. Brown $J$, Bussey $H$, Stewart RC: Yeast Skn7p functions in a eukaryotic two-component regulatory pathway. Embo J 1994, 13:5186-5194.

51. Hass C, Lohrmann J, Albrecht V, Sweere U, Hummel F, Yoo SD, Hwang I, Zhu T, Schäfer E, Kudla J, et al: The response regulator 2 mediates ethylene signalling and hormone signal integration in Arabidopsis. EMBO J 2004, 23:3290-3302.

52. Veerabagu M, Elgass K, Kirchler T, Huppenberger $\mathrm{P}$, Harter K, Chaban C, Mira-Rodado V: The Arabidopsis B-type response regulator 18 homomerizes and positively regulates cytokinin responses. Plant J 2012, 72:721-731.

53. van der Graaff EE, Hooykaas PJJ, Auer CA: Altered development of Arabidopsis thaliana carrying the Agrobacterium tumefaciens ipt gene is partially due to ethylene effects. Plant Growth Regul 2001, 34:305-315.

54. Su W, Howell SH: A single genetic locus, Ckrl, defines Arabidopsis mutants in which root growth Is resistant to low concentrations of cytokinin. Plant Physiol 1992, 99:1569-1574.

55. Brenner WG, Ramireddy E, Heyl A, Schmülling T: Gene regulation by cytokinin in Arabidopsis. Front Plant Sci 2012, 3:8.

56. Vogel JP, Schuerman P, Woeste K, Brandstatter I, Kieber JJ: Isolation and characterization of Arabidopsis mutants defective in the induction of ethylene biosynthesis by cytokinin. Genetics 1998, 149:417-427.

57. Chory J, Reinecke D, Sim S, Washburn T, Brenner M: A role for cytokinins in de-etiolation in Arabidopsis (det mutants have an altered response to cytokinins). Plant Physiol 1994, 104:339-347.

58. Street AH: Plant Tissue and Cell Culture. Oxford: Blackwell Scientific Publications; 1977

59. Deikman J, Hammer P: Induction of anthocyanin accumulation by cytokinins in Arabidopsis thaliana. Plant Physiol 1995, 108:47-57.

60. Kubasek WL, Shirley BW, McKillop A, Goodman HM, Briggs W, Ausubel FM: Regulation of flavonoid biosynthetic genes in germinating Arabidopsis seedlings. Plant Cell 1992, 4:1229-1236.

61. Pelletier M, Burbulis I, Winkel-Shirley B: Disruption of specific flavonoid genes enhances the accumulation of flavonoid enzymes and end-products in Arabidopsis seedlings. Plant Mol Biol 1999, 40:45-54

62. Richmond $A E$, Lang A: Effect of kinetin on protein content and survival of detached Xanthium leaves. Science 1957, 125:650-651.

63. Smart CM, Scofield SR, Bevan MW, Dyer TA: Delayed leaf senescence in tobacco plants transformed with tmr, a gene for cytokinin production in Agrobacterium. Plant Cell 1991, 3:647-656.

64. Gan S, Amasino RM: Inhibition of leaf senescence by autoregulated production of cytokinin. Science 1995, 270:1986-1988. 
65. Oh SA, Park JH, Lee Gl, Paek KH, Park SK, Nam HG: Identification of three genetic loci controlling leaf senescence in Arabidopsis thaliana. Plant J 1997, 12:527-535.

66. Skylar A, Wu X: Regulation of meristem size by cytokinin signaling. $J$ Integr Plant Biol 2011, 53:446-454.

67. Giulini A, Wang J, Jackson D: Control of phyllotaxy by the cytokinin-inducible response regulator homologue ABPHYL1. Nature 2004, 430:1031-1034.

68. Miyawaki K, Matsumoto-Kitano M, Kakimoto T: Expression of cytokinin biosynthetic isopentenyltransferase genes in Arabidopsis: tissue specificity and regulation by auxin, cytokinin, and nitrate. Plant J 2004, 37:128-138.

69. Werner T, Motyka V, Laucou V, Smets R, Van Onckelen H, Schmülling T: Cytokinin-deficient transgenic Arabidopsis plants show multiple developmental alterations indicating opposite functions of cytokinins in the regulation of shoot and root meristem activity. Plant Cell 2003, 15:2532-2550

70. Zhao Z, Andersen SU, Ljung K, Dolezal K, Miotk A, Schultheiss SJ, Lohmann $\mathrm{JU}$ : Hormonal control of the shoot stem-cell niche. Nature 2010, 465:1089-1092.

71. Dello loio R, Linhares FS, Sabatini S: Emerging role of cytokinin as a regulator of cellular differentiation. Curr Opin Plant Biol 2008, 11:23-27.

72. Dello loio R, Linhares FS, Scacchi E, Casamitjana-Martinez E, Heidstra R, Costantino P, Sabatini S: Cytokinins determine Arabidopsis root-meristem size by controlling cell differentiation. Curr Biol 2007, 17:678-682.

73. Kuderova A, Urbankova I, Valkova M, Malbeck J, Brzobohaty B, Nemethova D, Hejatko J: Effects of conditional IPT-dependent cytokinin overproduction on root architecture of Arabidopsis seedlings. Plant Cell Physio/ 2008, 49:570-582

74. Cary AJ, Liu W, Howell SH: Cytokinin action is coupled to ethylene in its effects on the inhibition of root and hypocotyl elongation in Arabidopsis thaliana seedlings. Plant Physiol 1995, 107:1075-1082.

75. Li Y, Hagen G, Guilfoyle TJ: Altered morphology in transgenic tobacco plants that overproduce cytokinins in specific tissues and organs. Dev Biol 1992, 153:386-395.

76. Alonso JM, Hirayama T, Roman G, Nourizadeh S, Ecker JR: EIN2, a bifunctional transducer of ethylene and stress responses in Arabidopsis. Science 1999, 284:2148-2152.

77. Hansen M, Chae HS, Kieber JJ: Regulation of ACS protein stability by cytokinin and brassinosteroid. Plant J 2009, 57:606-614

78. Roman G, Lubarsky B, Kieber JJ, Rothenberg M, Ecker JR: Genetic analysis of ethylene signal transduction in Arabidopsis thaliana: five novel mutant loci integrated into a stress response pathway. Genetics 1995, 139:1393-1409.

79. Ruzicka K, Simaskova M, Duclercq J, Petrasek J, Zazimalova E, Simon S, Friml J, Van Montagu MC, Benkova E: Cytokinin regulates root meristem activity via modulation of the polar auxin transport. Proc Natl Acad Sci U S A 2009, 106:4284-4289.

80. Kim K, Ryu H, Cho YH, Scacchi E, Sabatini S, Hwang I: Cytokinin-facilitated proteolysis of ARABIDOPSIS RESPONSE REGULATOR 2 attenuates signaling output in two-component circuitry. Plant J 2012, 69:934-945.

81. Takahashi N, Kajihara T, Okamura C, Kim Y, Katagiri Y, Okushima Y, Matsunaga S, Hwang I, Umeda M: Cytokinins control endocycle onset by promoting the expression of an APC/C activator in Arabidopsis roots. Curr Biol 2013, 23:1812-1817.

82. Müller D, Leyser O: Auxin, cytokinin and the control of shoot branching. Ann Bot 2011, 107:1203-1212.

83. Domagalska MA, Leyser O: Signal integration in the control of shoot branching. Nat Rev Mol Cell Biol 2011, 12:211-221.

84. Leyser O: The control of shoot branching: an example of plant information processing. Plant Cell Environ 2009, 32:694-703.

85. Ongaro V, Leyser O: Hormonal control of shoot branching. J Exp Bot 2008, 59:67-74.

86. Leyser O: The fall and rise of apical dominance. Curr Opin Genet Dev 2005, 15:468-471.

87. Pillay I, Railton ID: Complete release of axillary buds from apical dominance in intact, light-grown seedlings of Pisum sativum L. following a aingle application of cytokinin. Plant Physiol 1983, 71:972-974.

88. Bartrina I, Otto E, Strnad M, Werner T, Schmülling T: Cytokinin regulates the activity of reproductive meristems, flower organ size, ovule formation, and thus seed yield in Arabidopsis thaliana. Plant Cell 2011, 23:69-80.

89. Heyl A, Ramireddy E, Brenner WG, Riefler M, Allemeersch J, Schmülling T: The transcriptional repressor ARR1-SRDX suppresses pleiotropic cytokinin activities in Arabidopsis. Plant Physiol 2008, 147:1380-1395.
90. Alvarez JM, Vidal EA, Gutierrez RA: Integration of local and systemic signaling pathways for plant N responses. Curr Opin Plant Biol 2012, 15:185-191.

91. Cortizo M, Alvarez JM, Rodriguez A, Fernandez B, Ordas RJ: Cloning and characterization of a type-A response regulator differentially expressed during adventitious shoot formation in Pinus pinea L. J Plant Physio/ 2010, 167:1023-1026.

92. Tsai YC, Weir NR, Hill K, Zhang W, Kim HJ, Shiu SH, Schaller GE, Kieber JJ: Characterization of genes involved in cytokinin signaling and metabolism from rice. Plant Physiol 2012, 158:1666-1684.

93. Earley KW, Haag JR, Pontes O, Opper K, Juehne T, Song K, Pikaard CS: Gateway-compatible vectors for plant functional genomics and proteomics. Plant J 2006, 45:616-629.

94. Clough SJ, Bent AF: Floral dip: a simplified method for Agrobacteriummediated transformation of Arabidopsis thaliana. Plant J 1998, 16:735-743.

95. Kurepa J, Smalle JA: Assaying transcription factor stability. Methods Mol Biol 2011, 754:219-234

96. Graan T, Ort DR: Quantitation of the rapid electron donors to P700, the functional plastoquinone pool, and the ratio of the photosystems in spinach chloroplasts. J Biol Chem 1984, 259:14003-14010.

97. Harding EW, Tang W, Nichols KW, Fernandez DE, Perry SE: Expression and maintenance of embryogenic potential is enhanced through constitutive expression of AGAMOUS-Like 15. Plant Physiol 2003, 133:653-663.

98. Casamitjana-Martínez E, Hofhuis HF, Xu J, Liu CM, Heidstra R, Scheres B: Root-specific CLE19 overexpression and the sol1/2 suppressors implicate a CLV-like pathway in the control of Arabidopsis root meristem maintenance. Curr Biol 2003, 13:1435-1441.

doi:10.1186/1471-2229-14-28

Cite this article as: Kurepa et al.: Ectopic expression of the phosphomimic mutant version of Arabidopsis response regulator 1 promotes a constitutive cytokinin response phenotype. BMC Plant Biology 2014 14:28.

\section{Submit your next manuscript to BioMed Central and take full advantage of:}

- Convenient online submission

- Thorough peer review

- No space constraints or color figure charges

- Immediate publication on acceptance

- Inclusion in PubMed, CAS, Scopus and Google Scholar

- Research which is freely available for redistribution 